\title{
Surgical Treatment of Condylar Hyperplasia Associated with Dentofacial Deformity: Low Condylectomy, Articular Disc Repositioning, and Orthognathic Surgery
}

\author{
Tratamiento Quirúrgico de Hiperplasia Condilar Asociado a la Deformidad Dentofacial: \\ Condilectomía Baja, Reposicionamiento del Disco Articular y Cirugía Ortognática
}

Miguel Angelo Ribeiro Scheffer*; Bruno Tochetto Primo*; José Roberto Macarini**; Elken Gomes Rivaldo*** \& Pedro Antonio González Hernández ${ }^{* * *}$

SCHEFFER, M. A. R.; PRIMO, B. T.; MACARINI, J. R.; RIVALDO, E. G. \& HERNÁNDEZ, P. A. G. Surgical treatment of condylar hyperplasia associated with dentofacial deformity: low condylectomy, articular disc repositioning, and orthognathic surgery. Int. J. Odontostomat., 10(2):207-213, 2016.

ABSTRACT: Due to the complexity of the treatment of condylar hyperplasia associated with dentofacial deformities and its complications, if left untreated, the surgeon should be alert to these factors at the time of surgical planning to tailor the optimal therapy for an individual patient. This case report describes a patient with right condylar hyperplasia associated with dentofacial deformity who was treated surgically with low condylectomy, articular disc repositioning and anchoring, and orthognathic surgery, concomitantly, with stable results, satisfactory occlusion and facial harmony.

KEY WORDS: orthognathic surgery, mandibular condylar hyperplasia, condylectomy, facial asymmetry.

\section{INTRODUCTION}

Condylar hyperplasia $(\mathrm{CH})$ is a rare developmental malformation that causes overdevelopment of the mandible, creating functional and esthetic problems (Norman \& Painter, 1980). Overgrowth of the condyle(s) can cause facial asymmetry and occlusal alterations leading to malocclusions and temporomandibular disorders, such as deviation and limitation of mouth opening, pain, and joint sounds (Nitzan et al., 2008). The growth process is self-limiting, but as long as it remains active, asymmetry will progress along with associated occlusal alterations.

Some $\mathrm{CH}$ classification systems have been proposed. Obewegeser \& Makek (1986) classified CH into three categories: hemimandibular hyperplasia, causing asymmetry in the vertical plane; hemimandibular elongation, resulting in asymmetry in the transverse plane; and a combination of the two entities. Nitzan et al., also classified $\mathrm{CH}$ into three categories: vertical (similar to hemimandibular hyperplasia), transverse (comparable to hemimandibular elongation), or combined.

Wolford et al. (2014a), proposed a classification system to place patients with $\mathrm{CH}$ into categories based on histological, clinical and imaging characteristics, effects on the jaws and facial structures, and rate of occurrence. Four major categories were defined. $\mathrm{CH}$ type 1 refers to an accelerated and prolonged growth aberration of the "normal" mandibular condylar growth mechanism, causing a predominantly horizontal growth vector and resulting in prognathism that can occur bilaterally $(\mathrm{CH}$ type $1 \mathrm{~A})$ or unilaterally $(\mathrm{CH}$ type $1 \mathrm{~B})$. $\mathrm{CH}$ type 2 refers to enlargement of the mandibular condyle caused by an osteochondroma, resulting in predominantly unilateral vertical overgrowth and elongation of the mandible and face. It is also divided

\footnotetext{
Department of Oral and Maxillofacial Surgery, School of Dentistry, Universidade Luterana do Brasil (ULBRA), Canoas, Brazil.

" Private Dental Clinic, Canoas, Brazil.

*** Department of Dental Prothesis, School of Dentistry, Universidade Luterana do Brasil (ULBRA), Canoas, Brazil.
} 
into two subgroups, $\mathrm{CH}$ type $2 \mathrm{~A}$ has a predominantly vertical growth vector and enlargement of the condylar head, but without exophytic tumor extensions, whereas $\mathrm{CH}$ type $2 \mathrm{~B}$ grows vertically but develops horizontal exophytic tumor growth off the condyle. $\mathrm{CH}$ type 3 includes other rare, benign tumors and $\mathrm{CH}$ type 4 includes malignant tumors arising from the mandibular condyle that can cause enlargement.

It is important that the surgeon are able to make the diagnosis of $\mathrm{CH}$, understand the nature of the condition and its progression if untreated, recognize the ages for surgical intervention to minimize further adverse effects on facial growth and development in younger patients, and be aware of the surgical protocols to comprehensively and predictably treat all forms of $\mathrm{CH}$.

The objective of this article is to report the case of a patient with a diagnosis of unilateral $\mathrm{CH}$, anterior disc displacement, and dentofacial deformity who was treated with low condylectomy, articular disc repositioning and anchoring, and orthognathic surgery, describing the surgical planning and technique used as a way to help dental surgeons in the management of these cases.

\section{CASE REPORT}

The present study was approved by the Research Ethics Committee at University Luterana of Brazil (ULBRA), Canoas (Protocol No. 1.294.082).

A 48-year-old man presented with the esthetic chief complaints of facial asymmetry and difficulty chewing and speaking. The patient had no history of systemic disease, allergy, previous surgery, or use of continuous medication. He reported that the mandible continued to grow, increasing facial asymmetry, and pain was felt at the right temporomandibular joint (TMJ).

On clinical examination, facial asymmetry was evident as a result of mandibular deviation to the left, mandibular prognathism, maxillary retrognathism, and anterior and posterior crossbite (Fig. 1). Mouth opening was limited with deviation to the left during condylar translation. Based on the information reported by the patient and clinical data, he was referred for imaging evaluation of the TMJs.

A computed tomography (CT) scan showed change in the morphology of the right mandibular

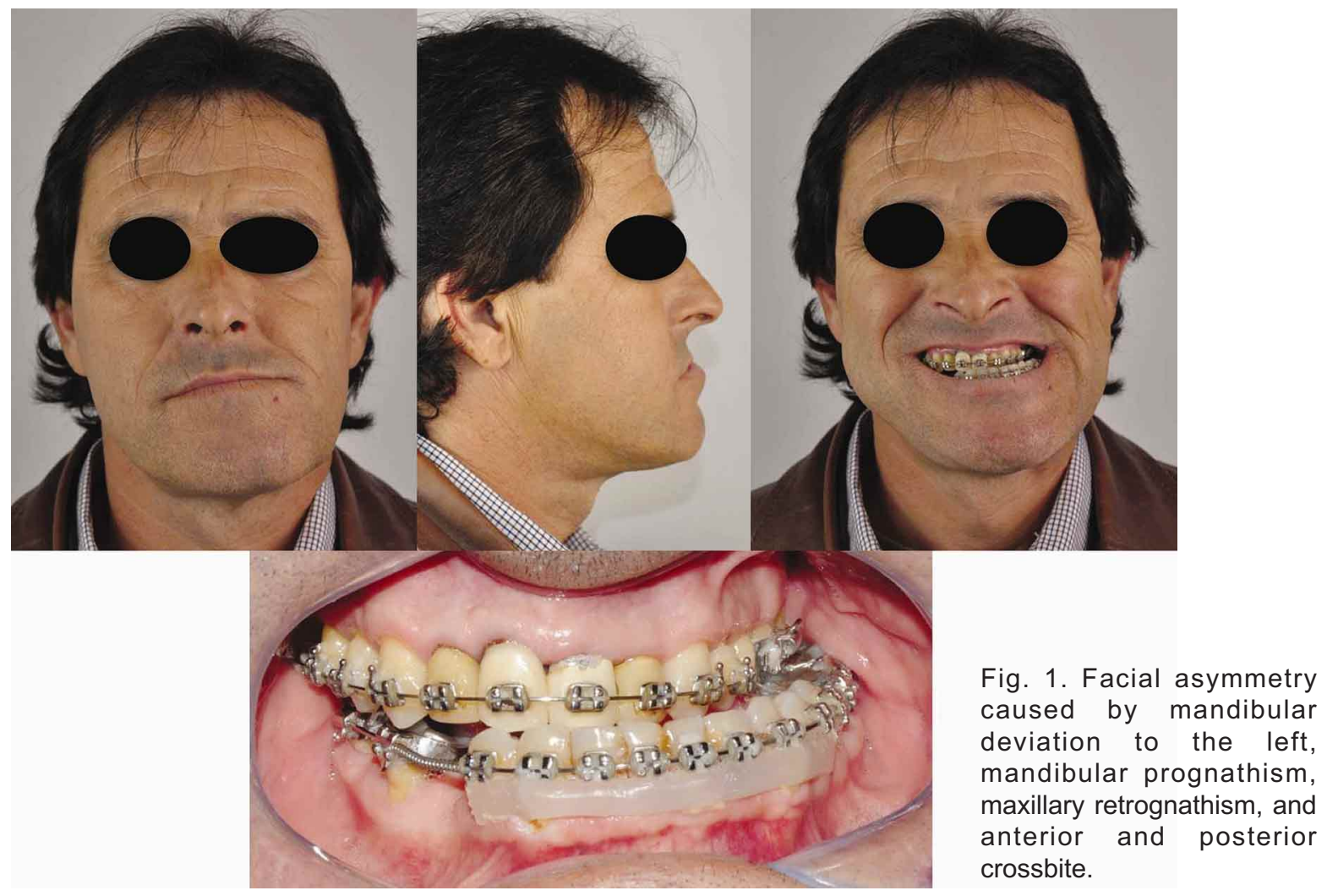


condyle, with increased size anteroposteriorly and mediolaterally in greatly exaggerated dimension (Fig. 2A-B). Nuclear magnetic resonance showed an anteriorly displaced disc, with no reduction on mouth opening. The left TMJ and articular disc remained unchanged. On bone scintigraphy, the right mandibular condyle showed bone metabolic activity (Fig. 2C). The diagnosis of right $\mathrm{CH}$ associated with dentofacial deformity was made.

Concomitant performance of low condylectomy of the right mandibular condyle, disc repositioning and anchoring, and orthognathic surgery was indicated for treatment. The treatment plan included presurgical orthodontic treatment to align and level the dental arches by means of dental decompensation. The patient accepted the treatment plan and was fully informed of possible surgical complications, giving written consent to treatment and for publication of this case report and any accompanying images.

Surgery was performed under general anesthesia with nasotracheal intubation. Surgical access was gained via a right preauricular, intra-aural approach, with dissection in planes to the temporal fascia to expose the TMJ capsule. Access was obtained to the upper and lower joint spaces of the TMJ and condylar process, where a low condylectomy was performed with removal of approximately $8 \mathrm{~mm}$ of the condyle. The condyle was then reshaped and the articular disc was repositioned. Part of the retrodiscal tissue was removed and the disc was stabilized with three $1.7 \mathrm{~mm}$ Mitek titanium mini-anchors (DePuy - J\&J) with 3.0 multibraided polyester sutures. The first anchor was placed in the posterolateral aspect of the condyle and sutured to the disc and retrodiscal tissues. The second and third anchors were placed in the zygomatic arch and in the condylar neck and also sutured to the articular disc to seat the condyle into the joint cavity, since it was shallow and there was a possibility of condyle dislocation, and the purpose of anchoring is to maintain the joint structure (condyle, disc, and joint cavity) in close relation.

The orthognathic surgical procedure started with mandibular setback and repositioning to the right. Maxillary osteotomies were performed to advance the maxilla and correct the occlusal cant. Miniplate and screw systems of $2.0 \mathrm{~mm}$ and $1.5 \mathrm{~mm}$ were used for fixation of bone segments.

Anatomopathologic findings revealed a lesion with bony proliferation and hyalinized cartilage covered by a cartilaginous cap, compatible with an osteochondroma.

The postoperative period was uneventful. The patient was hospitalized for 2 days and received antibiotics, anti-inflammatory drugs, and analgesics. The patient reported impaired sensitivity of the lower lip and complained of paresthesia, returning to normal 4 months after surgery. At 6-month follow-up, the patient had no complaints, had returned to work and resumed his normal diet, showing stable results, satisfactory occlusion, and facial harmony (Fig. 3A$B)$. The 6-month control radiograph showed steady maintenance of anchoring devices in place and bone alignment (Fig. 3C).

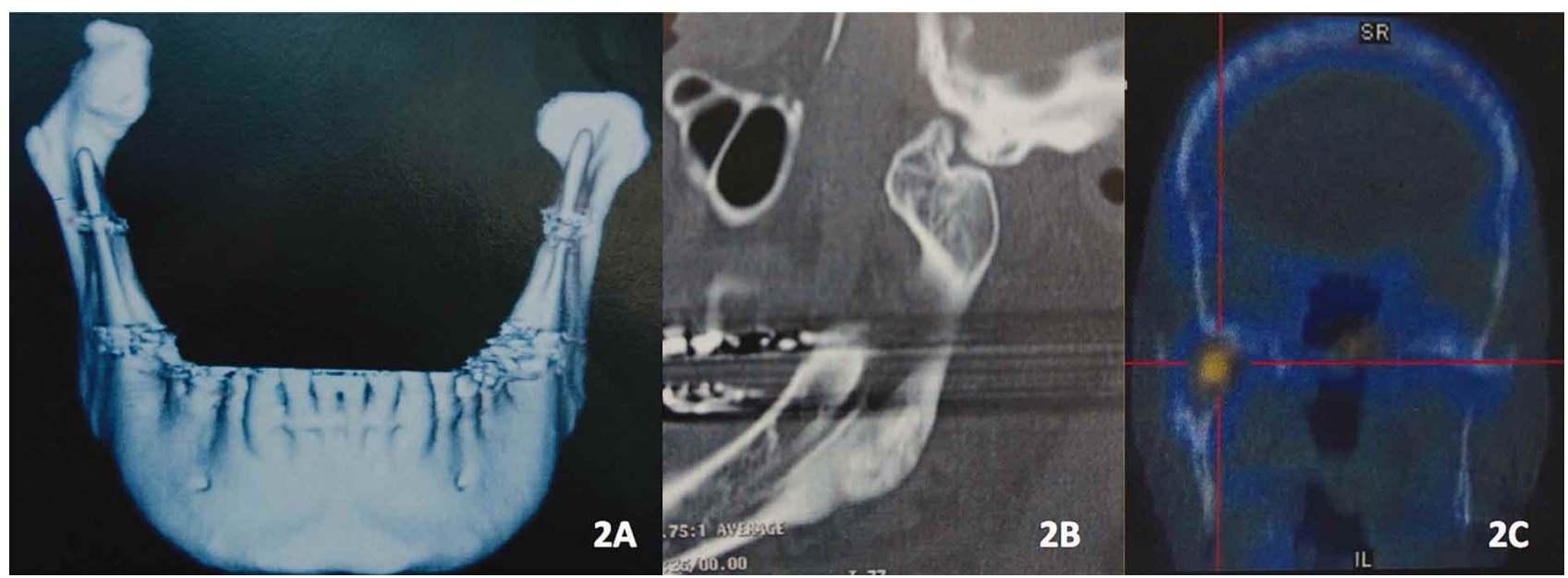

Fig. 2. A and B- Computed tomography scan showing the condyle with increased size anteroposteriorly and mediolaterally. C- Bone scintigraphy showing the right mandibular condyle with bone metabolic activity. 


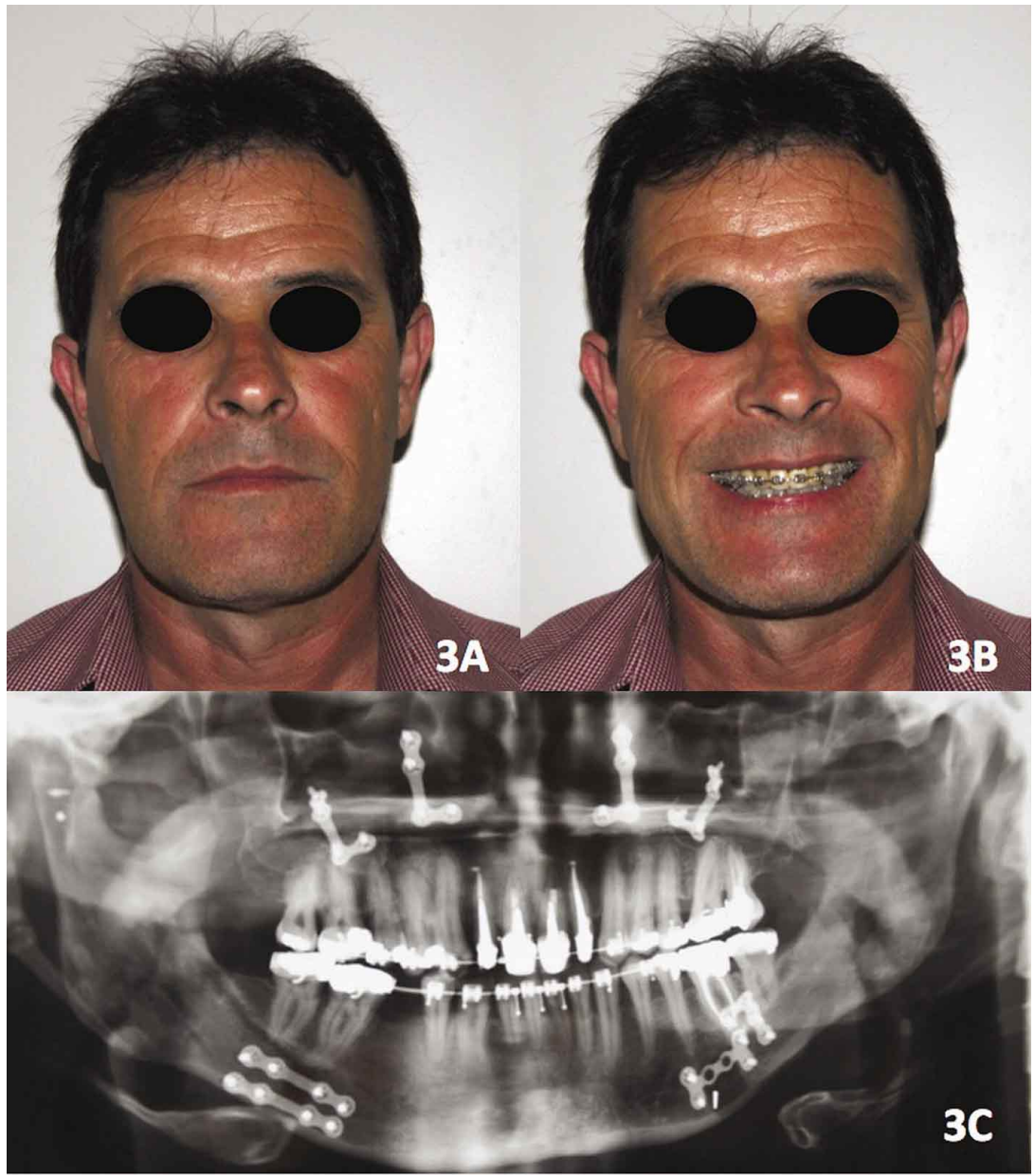

Fig. 3. A and 3- At 6-month follow-up, stable results, satisfactory occlusion and facial harmony were obtained. C- Panoramic radiograph showing the arrangement and steady maintenance of anchoring devices in place.

\section{DISCUSSION}

The etiology and pathogenesis of $\mathrm{CH}$ remain unclear. It is still unknown what triggers a condyle to suddenly start growing and become hyperplastic. Suggested theories include trauma, excessive proliferation in repair, infection, hormonal influences, osteoarthritis, hypervascularity, and a possible genetic influence (Villanueva-Alcojol et al., 2011). According to the classification system proposed by Wolford et al. (2014a), in the present case, the patient's CH could be diagnosed as type 2B, i.e., unilateral condylar growth caused by an osteochondroma that leads to vertical elongation of the ipsilateral mandible, with horizontal exophytic tumor growth off the condyle often extending anteriorly and medially, with a significantly enlarged and deformed condyle.
The diagnosis of $\mathrm{CH}$ can be made by a combination of clinical and radiological examinations. Several methods have been used, including radiography, bone scintigraphy, and histopathological evaluation. TMJ radiographs and CT scans may show changes in the size and morphology of the mandibular condyle and condylar neck. A patient's complaint of worsening functional and esthetic changes, photograph records, analysis of dental models in occlusion and radiographic evaluation (frontal and lateral views) by superimposition can be used as an initial diagnostic method (Rodrigues \&Castro, 2015). Bone scintigraphy is an option for visualizing hyperactivity in the condyle. Several studies have demonstrated the clinical relevance of this technique to patients with $\mathrm{CH}$, 
because this method is able to identify those with persistent unilateral condylar activity. The radioactive isotope is technetium 99, and increased radionuclide uptake by a hyperplastic condyle can be an indication of abnormal growth (5). A meta-analysis conducted by Saridin et al. (2011) indicates that an activity difference of more than $10 \%$ between the right and left condyles found on bone scintigraphy is suggestive of $\mathrm{CH}$. In the present case, all the aforementioned methods were used for the diagnosis of $\mathrm{CH}$. The patient had functional complaints (e.g. dysphagia and dyslalia) and esthetic complaints with progressive worsening over time, imaging tests showed that the shape of the right mandibular condyle was altered, a comparison of plaster dental casts showed progressive occlusal changes, and bone scintigraphy revealed increased metabolic activity in the right condyle. One of the patient's complaints was a gradual reduction in mouth opening, probably due to the continued condylar growth that caused limitation of mouth opening during condylar translation by locking of the joint on the articular eminence.

Clinically, patients with $\mathrm{CH}$ type 2 may have increased unilateral mandibular vertical height, increased soft tissue volume on the affected side of the face, low mandibular plane angle, vertical and transverse chin asymmetry, with a shift to the contralateral side, compensatory downward growth of the ipsilateral maxillary dentoalveolus, open bite on the affected side, and transverse cant of the occlusal plane (Rodrigues \& Castro).

Histologically, the osteochondroma consists of a proliferative bony mass covered by a cap of fibrocartilage and hyaline cartilage surrounded by fibrous tissue of the perichondrium, and ossification in the deep portion of the cartilage. The chondrocytes are arranged as rows perpendicular to the surface of the lesion and may overlie a zone of endochondral ossification, resulting in fusion of the cancellous bone with the normal underlying bone. The cartilaginous islands in the subcortical bone may have a direct correlation with the scintigraphic activity. These islands are mini-growth centers producing bone, causing enlargement of the condyle (Rodrigues \& Castro; Vezeau et al., 1995).

In the literature review by Ord et al. (2010), among 44 surgically treated cases, the preauricular incision was the most common surgical approach. However, the Risdon (submandibular) approach was also mentioned as being used for excision of the lesion in the mandibular condyle. Vertical osteotomy of the mandibular ramus was also reported. In the present case, and in all other cases managed by the surgical team, a preauricular incision is always the surgical approach of choice, because it provides sufficient visualization to perform the condylectomy and articular disc repositioning, even in this complex case of removal of a large hyperplastic condyle.

Wolford et al. (2014b) reported a series of 37 patients with $\mathrm{CH}$ type 2 treated with the Wolford protocol (concomitant condylectomy, articular disc repositioning and orthognathic surgery) with postoperative follow-up of 48 months. There was only one case of recurrence, a patient who was first diagnosed with $\mathrm{CH}$ type 1 based on facial morphology, imaging tests, and facial growth pattern. The patient was treated with high condylectomy (with removal of 4-5 mm of the condyle), disc repositioning, and doublejaw orthognathic surgery. However, histopathological examination revealed an osteochondroma, and the tumor continued to grow, requiring reoperation 14 months later. A low condylectomy of 8 to $10 \mathrm{~mm}$ and orthognathic surgery were performed, with a stable result at 4 years after surgery. This case confirms the importance of performing a low condylectomy to eliminate the tumor. In that study, all 37 patients showed statistically significant improvement in pain, headaches, mandibular function, and diet. The treatment protocol includes performing a low condylectomy at the junction of the mandibular condyle and condylar neck to completely remove the tumor and preserve the condylar neck. In patients with osteochondroma, the affected mandibular condyle will enlarge, and the neck will become thicker anteroposteriorly and mediolaterally. This thickening of the neck allows reshaping of the remaining neck to serve as a "new condyle". The articular disc can be repositioned onto the "new condyle" and stabilized. If the contralateral articular disc has also been displaced and is salvageable, that disc should also be repositioned and stabilized using a fixation technique with anchors. An ipsilateral sagittal split osteotomy should be performed to thrust the disc and the "new condyle" into the articular fossa. To correct any associated facial deformities, contralateral mandibular ramus sagittal split osteotomy, maxillary osteotomy and genioplasty can be performed. However, TMJ surgery must be performed first, followed at a second stage by orthognathic surgery to prevent occlusal changes (Wolford et al., 2014b). The severity of the deformity, however, may warrant surgery at an earlier age and, following it, an option would be to perform the unilate- 
SCHEFFER, M. A. R.; PRIMO, B. T.; MACARINI, J. R.; RIVALDO, E. G. \& HERNÁNDEZ, P. A. G. Surgical treatment of condylar hyperplasia associated with dentofacial deformity: low condylectomy, articular disc repositioning, and orthognathic surgery. Int. J. Odontostomat., 10(2):207-213, 2016.

ral condylectomy and, as a second stage, orthognathic surgery after cessation of growth (Rodrigues \& Castro). In the present case, orthognathic surgery and TMJ surgery were performed concomitantly because the patient was an adult (growth phase ceased) and was unwilling to undergo two surgical procedures at different times. After the initial period and edema reduction, the patient reported no TMJ pain, there was no limitation of mouth opening and mandibular growth ceased.

The low condylectomy will remove all remnants of fibrocartilage from the condyle, resulting in the cortical and medullary bone of the condylar neck in juxta-approximation to the articular disc (Wolford et al., $2014 b)$. The risk of recurrence of benign tumors is low after surgical removal. This protocol will provide predictable and stable outcomes and optimize functional and esthetic results. If the disc is not salvageable, a TMJ total joint prosthesis can be used for ipsilateral or contralateral TMJ reconstruction (Rodrigues \& Castro).

According to Wolford et al. (2014b), the advantages of this surgical protocol are as follows: 1 ) It eliminates the TMJ pathologic entity while maintaining the mandibular bone and articular disc to function as the TMJ; 2) It allows the simultaneous performance of orthognathic surgery, enabling restoration of the stomatognathic system and facial balance; 3 ) It eliminates or significantly reduces the patient's pain; 4) All surgical procedures can be completed in a single session (although they can be performed in stages, for example in patients during the growth phase); 5) It eliminates the need for autografts, thus eliminating donor site morbidity; 6) It eliminates the need for postoperative maxillomandibular fixation because the fixation system is able to stabilize the osteotomies; 7) The surgical technique effectively maintains the preoperative incisal opening; and 8) Patients' quality of life is significantly improved.

The surgery for low condylectomy involves making surgical incisions at the TMJ through an external approach. The preauricular incision is the most common approach to the TMJ, although other surgical approaches have been reported. The surgical procedure has potential complications, including damage to adjacent structures such as nerves (cranial nerves $\mathrm{V}$ and $\mathrm{VII}$ ), vessels, the ear, parotid gland, base of the skull, and middle cranial fossa. Infections and secondary complications, such as ankylosis, functional disorders, and increased postoperative pain, should also be considered (Hoffman et al., 2015). In the present case, there were no peri- or postoperative complications. The edema and pain were compatible with the magnitude of surgery, and the patient received analgesic and anti-inflammatory drugs without complaints. During the first 10 days, the patient had trismus and difficulty chewing due to TMJ and orthognathic surgery and was therefore given a liquid and soft diet during this period.

A major concern in TMJ surgery is inadvertent injury to the maxillary artery, given its bleeding potential and the well-known need for hemostasis. In low condylectomy, the risk of injury to the maxillary artery is particularly high because the artery runs posterior to the condyle and just above the sigmoid notch. In the present case, the greatest difficulty was found in removing the hyperplastic condyle due to its large size. Thus, the low condylectomy was performed carefully using an instrument to protect the posterior region of the condyle. In addition, the osteotomy with a drill directed medially to the condyle was not completed, and chisels were used to reduce the chance of maxillary artery injury and complete the procedure.

In the present case, a patient with right $\mathrm{CH}$ associated with dentofacial deformity was treated surgically with low condylectomy, articular disc repositioning and anchoring, and orthognathic surgery, concomitantly, with stable results, satisfactory occlusion and facial harmony at 6 months after surgery.

SCHEFFER, M. A. R.; PRIMO, B. T.; MACARINI, J. R.; RIVALDO, E. G. \& HERNÁNDEZ, P. A. G. Tratamiento quirúrgico de hiperplasia condilar asociado a la deformidad dentofacial: condilectomía baja, reposicionamiento del disco articular y cirugía ortognática. Int. J. Odontostomat., 10(2):207-213, 2016.

RESUMEN: Debido a la complejidad del tratamiento de la hiperplasia condilar asociada con deformidades dentofaciales y sus complicaciones, si no se trata, el cirujano debe estar alerta ante estos factores en el momento de la planificación quirúrgica para adaptar la terapia óptima para cada paciente. Este caso describe un paciente con hiperplasia condilar derecha asociada con la deformidad dentofacial que fue tratado quirúrgicamente con condilectomía baja, reposicionamiento y anclaje del disco articular, y la cirugía ortognática, concomitantemente, con resultados estables, oclusión satisfactoria y armonía facial.

PALABRAS CLAVE: cirugía ortognática, hiperplasia condilar mandibular, condilectomía, asimetría facial. 
SCHEFFER, M. A. R.; PRIMO, B. T.; MACARINI, J. R.; RIVALDO, E. G. \& HERNÁNDEZ, P. A. G. Surgical treatment of condylar hyperplasia associated with dentofacial deformity: low condylectomy, articular disc repositioning, and orthognathic surgery. Int. J. Odontostomat., 10(2):207-213, 2016.

\section{REFERENCES}

Hoffman, D. \& Puig, L. Complications of TMJ surgery. Oral Maxillofac. Surg. Clin. North Am., 27(1):109-24, 2015.

Nitzan, D .W.; Katsnelson, A.; Bermanis, I.; Brin, I. \& Casap, N. The clinical characteristics of condylar hyperplasia: experience with 61 patients. J. Oral Maxillofac. Surg., 66(2):312-8, 2008.

Norman, J. E. \& Painter, D. M. Hyperplasia of the mandibular condyle. A historical review of important early cases with a presentation and analysis of twelve patients. $J$. Maxillofac. Surg., 8(3):161-75,1980.

Obwegeser, H. L. \& Makek, M. S. Hemimandibular hyperplasia--hemimandibular elongation. J. Maxillofac. Surg., 14(4):183-208, 1986.

Ord, R. A.; Warburton, G. \& Caccamese, J. F. Osteochondroma of the condyle: review of 8 cases. Int. J. Oral Maxillofac. Surg., 39(6):523-8, 2010.

Rodrigues, D. B. \& Castro, V. Condylar hyperplasia of the temporomandibular joint: types, treatment, and surgical implications. Oral Maxillofac. Surg. Clin. North Am., 27(1):155-67, 2015.

Saridin, C. P.; Raijmakers, P. G.; Tuinzing, D. B. \& Becking, A. G. Bone scintigraphy as a diagnostic method in unilateral hyperactivity of the mandibular condyles: a review and meta-analysis of the literature. Int. J. Oral Maxillofac. Surg., 40(1):11-7, 2011.

Vezeau, P. J.; Fridrich, K. L. \& Vincent, S. D. Osteochondroma of the mandibular condyle: literature review and report of two atypical cases. J. Oral Maxillofac. Surg., 53(8):95463, 1995.

Villanueva-Alcojol, L.; Monje, F. \& González-García, R. Hyperplasia of the mandibular condyle: clinical, histopathologic, and treatment considerations in a series of 36 patients. J. Oral Maxillofac. Surg., 69(2):44755, 2011.

Wolford, L. M.; Movahed, R. \& Perez, D. E. A classification system for conditions causing condylar hyperplasia. J. Oral Maxillofac. Surg., 72(3):567-95, 2014a.

Wolford, L. M.; Movahed, R.; Dhameja, A. \& Allen, W. R. Low condylectomy and orthognathic surgery to treat mandibular condylar osteochondroma: a retrospective review of 37 cases. J. Oral Maxillofac. Surg., 72(9):170428, 2014b.
Correspondence to:

Dr. Miguel Angelo Ribeiro Scheffer

Rua Casemiro de Abreu, 362

Boa Vista, Porto Alegre - RS

90020-061

BRAZIL

Phone/Fax: +55 5130611408

Email: mascheffer@gmail.com

Received: 04-01-2016

Accepted: 13-07-2016 